\title{
PRETREATMENT TUMOR VOLUME ESTIMATION BASED ON TOTAL SERUM PSA IN PATIENTS WITH LOCALIZED PROSTATE CANCER
}

\author{
Raphael Barroso Kato, Victor Srougi, Fernanda Aburesi Salvadori, Pedro Paulo \\ Marino Rodrigues Ayres, Katia Moreira Leite, Miguel Srougi
}

doi: $10.1590 / \mathrm{S1807-59322008000600009}$

Kato RB, Srougi V, Salvadori FA, Ayres PPMR, Leite KM, Srougi M. Pretreatment tumor volume estimation based on total serum PSA in patients with localized prostate cancer. Clinics. 2008;63:759-62.

OBJECTIVES: To establish a formula that estimates tumor volume in localized prostate cancer based on serum prostate specific antigen levels. One of the main prognostic variables in localized prostate cancer is tumor volume, which can be precisely defined only after prostate extirpation. The present study defines a simple method that allows for estimation of tumor volume before treatment, which can help to establish a better therapeutic strategy for each patient.

METHODS: From 1997 to 2002, 735 patients with prostate cancer of stagesT1c-T2c without any previous treatment were submitted to radical prostatectomy. Surgical specimens were evaluated by the same pathologist and the total tumor volume (in cc) and the relative tumor volume (as the percent of the total prostate volume) were determined using the grid morphometric method. Pretreatment serum prostate specific antigen was correlated with tumor volume in each patient using a linear regression model.

RESULTS: There were positive correlations between the serum levels of prostate specific antigen and the total tumor volume in $\mathrm{cc}(\mathrm{p}<0.001)$ and the relative tumor volume as a percentage $(\mathrm{p}<0.001)$. For each $\mathrm{ng} / \mathrm{ml}$ unit increment of serum prostate specific antigen, there was a $0.302 \mathrm{cc}$ increase in total tumor volume and a $0.7 \%$ increase in relative tumor volume. Total and percent tumor volume could be calculated, respectively, using the formulas Volume $(\mathrm{cc})=3.476+0.302 \times \mathrm{XSA}(\mathrm{ng} / \mathrm{ml})$ and Volume $(\%)=11.331$ +0.704 x prostate specific antigen $(\mathrm{ng} / \mathrm{ml})$.

CONCLUSIONS: Tumor volume in patients with prostate cancer can be determined before treatment based on the serum prostate specific antigen levels.

KEYWORDS: Prostate Cancer; Tumor Volume; Prognosis; Prostate Specific Antigen; Radical Prostatectomy.

\section{INTRODUCTION}

Studies of prostate cancer and its prognostic factors are of high importance to public health. Prostate cancer is frequent in males, representing $40 \%$ of malignant neoplasias in men and affecting $17.1 \%$ of all men. ${ }^{1}$ Epidemiological data show that prostate cancer is the second leading cause of cancer-related mortality in men, with lung cancer ranking first. ${ }^{1}$

The clinical challenge in treating prostate adenocarcinoma

Division of Urology, Faculdade de Medicina, Universidade de São Paulo São Paulo/SP, Brazil.

Email: kato_med91@yahoo.com.br

Tel.: 55113061.7000

Received for publication on July 19, 2008

Accepted for publication on August 22, 2008 is that only a small number of men will die from the disease. Therefore, it is necessary to establish criteria to distinguish between those cases that require treatment and those for whom routine management is a good choice. ${ }^{2}$ After prostate cancer is diagnosed, the main prognostic factors that define severity and disease evolution are the Gleason score of the biopsy, the level of prostate specific antigen (PSA) in the blood and tumor volume. ${ }^{3}$ The importance of tumor volume in the follow-up of prostate cancer patients was demonstrated in papers that related larger neoplasia volumes with characteristics that were indicative of a worse prognosis: capsular invasion, seminal vesicle invasion, a worse response to treatment and metastases to regional lymph nodes and bones..$^{2-5}$ The imaging methods that are currently used to determine prostate cancer volume are inaccurate and do not reflect the real extent of the disease. ${ }^{6}$ Thus, establishing a 
method to estimate tumor volume soon after diagnosis would be of great clinical relevance and would improve patient treatment.

The objective of this study was to investigate whether it is possible to predict tumor volume in prostate cancer patients by initial measurements of the PSA level.

\section{MATERIAL AND METHODS}

A retrospective study was conducted with 788 patients who were diagnosed with prostate adenocarcinoma, with disease at the T1b-T2c clinical stage. These patients underwent radical prostatectomy performed by a single surgeon (M.S.) between 1997 and 2002. The 53 patients who received preoperatory hormone therapy were excluded from this study; therefore, the final assessed group included 735 cases.

The patients' ages ranged from 41 to 79 years, with a mean of 63 years. For this study, the highest preoperative serum PSA level measured by the Tandem-R method was used. ${ }^{9}$

The surgical specimens were fixed in formalin and the whole gland was subjected to a histological study according to the recommendations of Bostwick and Foster. ${ }^{7}$ Tumor volume assessment was conducted with the aid of a grid, as described by Humphrey and Vollmer. ${ }^{8}$ During the microscopic examination, the areas of the gland that were infiltrated by tumor were outlined using a pen with permanent ink. The marked slides were then put on top of a grid and the percentage of squares that were occupied by the adenocarcinoma was calculated in relation to the whole area covered by the specimen. Thus, the tumor volume corresponded to the gland area occupied by the tumor and its absolute value was calculated by multiplying the tumor percentage by the gland's total weight.

The relationship between PSA levels and tumor volume was plotted on a dispersion graph and it was quantified by calculating the Pearson's correlation coefficient, with its respective $95 \%$ confidence interval $(95 \% \mathrm{CI})$. A linear regression model was generated to describe the relationship between the two variables.

The primary objective of the present study was to relate serum PSA levels to the outcomes of absolute tumor volume (in cc) and relative tumor volume (percentage of the gland infiltrated by tumor).

\section{RESULTS}

As shown in Figure 1, a statistically significant correlation was observed between the tumor volume in cc and serum PSA levels $(\mathrm{p}<0.001)$. Likewise, as shown in Figure 2, a positive correlation was demonstrated between

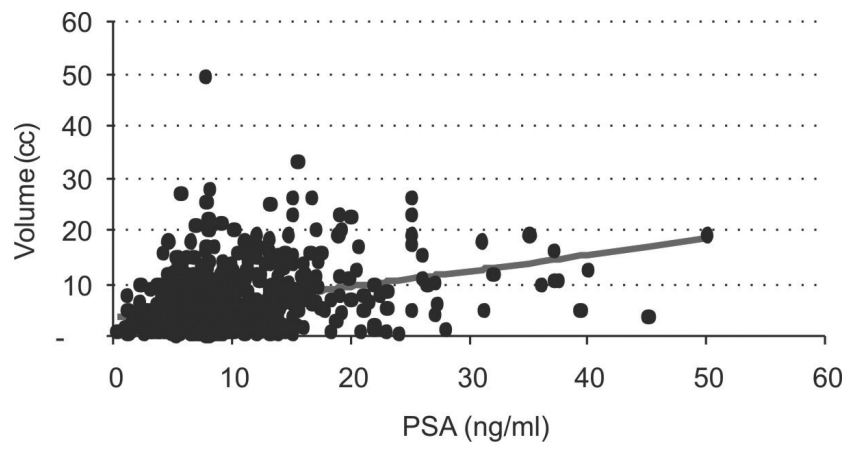

Figure 1 - Correlation between tumor volume (cc) and serum PSA levels (Pearson's correlation $=0.332$ [IC 95\%:0.266-0.395], $\mathrm{p}<0.001$ )

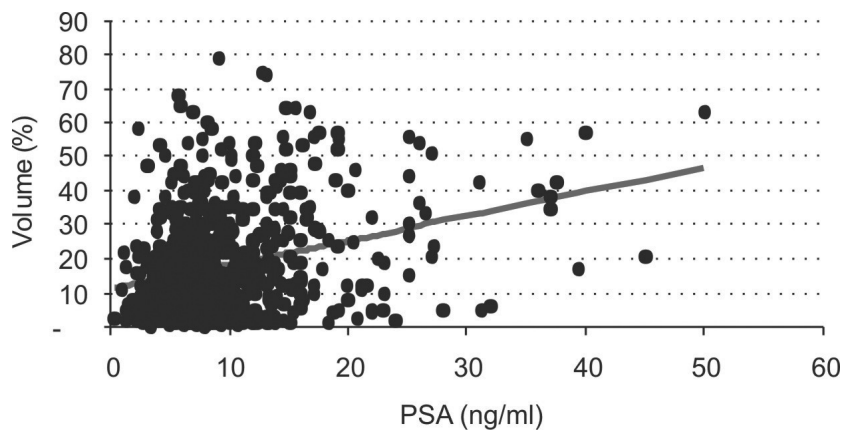

Figure 2 - Correlation between relative tumor volume (\%) and serum PSA levels (Pearson's correlation $=0.289$ [IC 95\%:0.221 -0.354$], \mathrm{p}<0.001$ )

the percentage of tumor volume and serum PSA levels $(\mathrm{p}<0.001)$. A statistical analysis of the data plotted in Figure 1 shows that, for each $1 \mathrm{ng} / \mathrm{ml}$ increment in serum PSA, the absolute tumor volume increases by $0.302 \mathrm{cc}$. The linear regression equation is:

Volume $(\mathrm{cc})=\mathbf{3 . 4 7 6}+\mathbf{0 . 3 0 2} \times$ PSA

The statistical analysis of the data plotted in Figure 2 shows that, for each $1 \mathrm{ng} / \mathrm{ml}$ increment in serum PSA, there is an increase of $0.7 \%$ in the percent tumor volume in relation to the entire gland. The linear regression equation is:

Volume $(\%)=11.331+0.704 \times$ PSA

\section{DISCUSSION}

In a previous study we analyzed the risk factor for a prostate carcinoma in patients with benign hyperplasia. ${ }^{10}$ In the present study, we demonstrate that, there is a direct relationship between PSA levels and tumor volume, both in terms of cc and tumor percentage, in patients with localized prostate cancer. Thus, it is possible to estimate tumor volume soon after disease diagnosis. This strategy would allow for more rational treatment planning for patients. 
The results presented here had a high level of consistency due to the large number of patients examined and because the tumor volume assessment was performed by a single observer (K.L.). This study is limited by the fact that the PSA measurements for selected patients were performed in different laboratories.

In a study of 320 patients, by Blackwell et al. ${ }^{6}$ demonstrated that preoperatory serum PSA levels were of great value in predicting not only the tumor volume, but also the pathological staging and risk of disease dissemination. Likewise, Bostwick and colleagues ${ }^{11-13}$ concluded that it is possible to predict tumor volume from initial PSA measurements. Partin and colleagues ${ }^{14}$ studied 56 patients who underwent radical prostatectomy and concluded that the percentage of the gland with tumor had higher predictive value than the absolute tumor volume when defining the pathological stage of the disease.

In contrast, after a five-year follow-up study of 185 patients who underwent radical prostatectomy, Epstein and colleagues ${ }^{15}$ concluded that the tumor volume measurement should not be routine practice in surgical pathology as it does not contribute any additional information regarding disease progression. They suggested that the Gleason score is a sufficient parameter for disease progression.

The medical literature indicates that, while controversial, the assessment of tumor volume soon after disease diagnosis might help to better define the aggressiveness of the neoplasia.

According to the data presented here, it is possible to predict the tumor volume at the time of disease diagnosis and thus adequately select the appropriate treatment for each patient. If the tumor is of small volume, radical curative treatment or patient observation with clinical follow-up is recommended. ${ }^{16}$ In contrast, if the tumor is of large volume, exclusive or adjuvant systemic treatment should be considered due to the high risk of metastasis. According to McNeal and colleagues, ${ }^{17} 62 \%$ of patients with tumor volumes larger than $16 \mathrm{cc}$ presented with distant metastases, while patients with tumor volumes smaller than $4 \mathrm{cc}$ presented with disease dissemination.

Thus, for those who value tumor volume estimates soon after diagnosis, the present study presents a simple mathematical instrument to calculate such a value, which may directly contribute to the selection of appropriate treatments for patients with prostate adenocarcinoma.

\section{ACKNOWLEDGEMENTS}

The authors are grateful to Adriana Sanudo for assistance with the statistical analysis.

\section{REFERENCES}

1. Hering FL, Srougi M. Urologia: Diagnóstico e tratamento. São Paulo. 1998; vol.1, p. 363.

2. Stamey TA, McNeal JE, Yemoto CM, Sigal BM, Johnstone IM. Biological determinants of cancer progression in men with prostate cancer. JAMA. 1999;281:1395-1400.

3. Stamey TA, McNeal JE, Freiha FS, Redwine E. Morphometric and clinical studies on 68 consecutive radical prostatectomies. J Urol. 1988;139:1235-41.

4. Babaian RJ, Troncoso P, Steelhammer LC, Lloreta-Trull J, Ramirez EI. Tumor volume and prostate specific antigen: implications for early detection and defining a window of curability. J Urol. 1995;154:180812.

5. Bostwick DG and Choi C. Prognostic factors in early prostate cancer. In: Urology Annual (ed.). New York, WW Norton. 1992; vol 6, pp. 66101.

6. Blackwell KL, Bostwick DG, Myers RP, Zincke H, Oesterling JE. Combining prostate specific antigen with cancer and gland volume to predict more reliably pathological stage: The influence of prostate specific antigen cancer density. J Urol. 1994;151:1565-70.
7. Bostwick DG and Foster CS. Examination in radical prostatectomy specimens: therapeutic and prognostic significance. In: Pathology of Prostate. Philadelphia, WB Saunders. 1998; vol 34, p. 172.

8. Humphrey PA and Vollmer RT: Intraglandular tumor extent and prognosis in prostatic carcinoma: aplication of a grid method to prostatectomy specimens. Hum Pathol. 1990;21:799-804.

9. Klee GG, Dodge LA, Zincke H, Oesterling JE. Measurement of serum prostate specific antigen using the IMx prostate specific antigen assay. J Urol. 1994;151:94-8.

10. Antunes AA, Freire Gde C, Aiello Filho D, Cury J, Srougi M. Analysis of the risk factors for incidental carcinoma of the prostate in patients with benign prostatic hyperplasia. Clinics. 2006;61:545-50

11. Bostwick DG, Graham SD, Napalkov P, Abrahamsson PA, Sant'Agnese PA, Algaba F et al: Staging of early prostate cancer: a proposed tumor volume-based prognostic index. Urology. 1993; 41:403-11.

12. Carter HB, Partin AW, Epstein JI, Chan DW, Walsh PC. The relationship of prostate specific antigen levels and residual tumor volume in stage A prostate cancer. J Urol. 1990;144:1167-70. 
13. Stamey TA, Yang N, Hay AR, McNeal JE, Freiha FS and Redwine E. Prostate-specific antigen as a serum marker for adenocarcinoma of the prostate. N Engl J Med. 1987;317:909-16.

14. Partin AW, Epstein JI, Cho KR, Gitttelsohn AM, Walsh PC. Morphometric measurent of tumor volume and per cent of gland involvement as predictors of pathological stage in clinical stage B prostate cancer. J Urol. 1989;141:341-45.

15. Epstein JI, Carmichael M, Partin AL, Walsh PC. Is tumor volume an independent predictor of progression following radical prostatectomy? A multivariate analysis of 185 clinical stage B adenocarcinomas of prostate with 5 years of followup. J Urol. 1993;149:1478-81.
16. Carvalhal GF, Humphrey PA, Thorson P, Yan Y, Ramos CG, Catalona WJ. Visual estimate of the percentage of carcinoma is an independent predictor of prostate carcinoma recurrence after radical prostatectomy. Cancer. 2000;89:6:1308-14.

17. McNeal JE, Villers AA, Redwine EA, Freiha FS and Stamey TA. Histological differentiation, cancer volume, and pelvic lymph node metastasis in adenocarcinoma of the prostate. Cancer. 1990;66:122533. 